\title{
Vector cardiogram and anatomy of atrial septal defect
}

\author{
A. C. ARntzenius, J. NAUtA, A. G. BROM, AND H. A. SNELlen \\ From the Departments of Cardiology and Thoracic Surgery, University Hospital, Leyden, The Netherlands
}

Before deciding to operate on a patient with an atrial septal defect, one must try to find out which type of atrial septal defect is to be closed. This is necessary because the success of the operation is primarily dependent on the localization of the defect in the atrial septum.

In an atrial septal defect of the dorsal ('secundum') type (Los, 1963) the operation risk is smaller than in a defect of the ventral ('primum') type.

If, as is customary in our hospital, the surgeon uses hypothermia for closing the dorsal type and extracorporeal circulation for closing the ventral type of atrial septal defect, the importance of differentiating between these two types is even greater. The use of the vector cardiogram helps to distinguish one from the other.

Previous authors (Silverblatt, Rosenfeld, Grishman, and Donoso, 1957; Hamer, 1958; ToscanoBarbosa, Brandenburg, and Burchell, 1956; Liebman and Nadas, 1960; Pileggi, Boccalandro, Ebaid, Malleta, Tranchesi, Macruz, and Décourt, 1961) have shown that the projection of the vector loop in the frontal plane has an upward counter-clockwise course in ventral atrial septal defect, whereas it has a downward clockwise course in the dorsal type.

No satisfactory explanation of this phenomenon has so far been found. In the course of the years we have observed a few exceptions to the general rule, and it seemed useful to re-evaluate this differential diagnosis.

\section{MATERIAL AND METHODS}

Between 1957 and 1961, 268 patients with an atrial septal defect were operated upon. At operation the defect was found to be of the dorsal type in 239 , and of the ventral type in 29 patients. The youngest patient was 1 year old and the oldest was 60 years of age.

A vector cardiogram was available for further examination in 152 of the 239 patients with a dorsal type of defect, and in all 29 of the patients with a ventral type of defect. Before operation a prediction had been made as to the anatomical type of atrial septal defect to be expected. The predictions were verified at subsequent operations.

The vector cardiograms were obtained with the aid of Burger's lead system (Burger, van Milaan, and Den Boer, 1952). They were divided into four groups, the first three constituting a subdivision of the dorsal type, and the fourth with the characteristics of the ventral type of atrial septal defect (A.S.D.).

\section{CLASSIFICATION OF VECTOR CARDIOGRAMS}

1. CLASSIC TYPE FOR A DORSAL A.S.D. In the frontal plane there is a clockwise rotation of the loop, passing underneath and often showing some retardation late in the right superior segment (Figs. 1 to 3).

2. NON-CLASSIC TYPE FOR A DORSAL A.S.D. This type cannot be included either in group 1 or in group 3 . The vector loop shows some peculiarities, such as a small counter-clockwise loop on the left (Fig. 4) or a loop extending very far to the left and remaining virtually horizontal (Fig. 5).

3. FIGURE-OF-EIGHT VECTOR LOOP IN FRONTAL PLANE IN A DORSAL A.S.D. In the figure-of-eight QRS loop in the frontal plane the point of intersection lies near the $\mathrm{O}$-point, and the loop extends about as far above as below the O-line (Figs. 6 and 7).

4. VECTOR LOOP IN A VENTRAL A.S.D. The frontal loop passes overhead and counter-clockwise (Fig. 8).

\section{ANATOMICAL CLASSIFICATION}

The anatomical type of A.S.D. was established at operation. The following types were distinguished.

DORSAL ('SECUNDUM') DEFECTS Five types of defect are shown in Fig. 9. These are as follows: type 1, a central defect, with an edge all round; type 2 , a defect without a caudal edge; type 3 , the 'sinus venosus' type; type 4, a defect without a dorsal edge; and type 5, a defect without a dorsal or a caudal edge. 


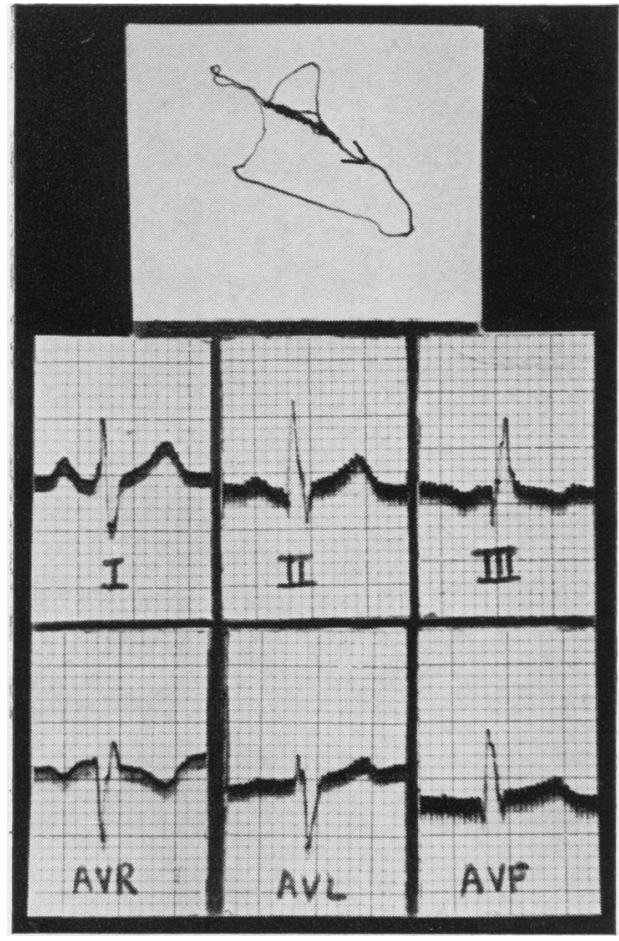

FIG. 1

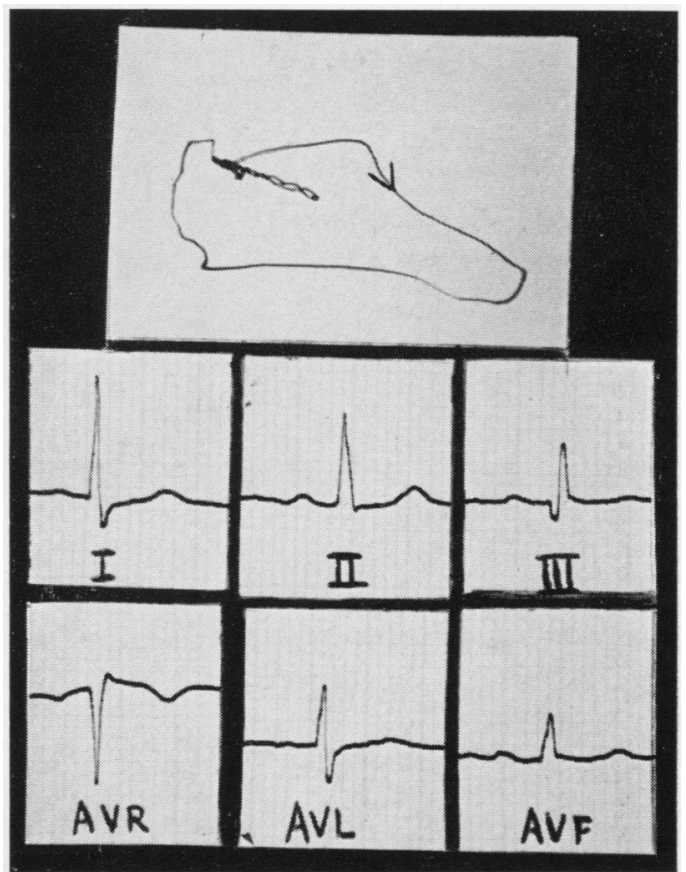

FIG. 2

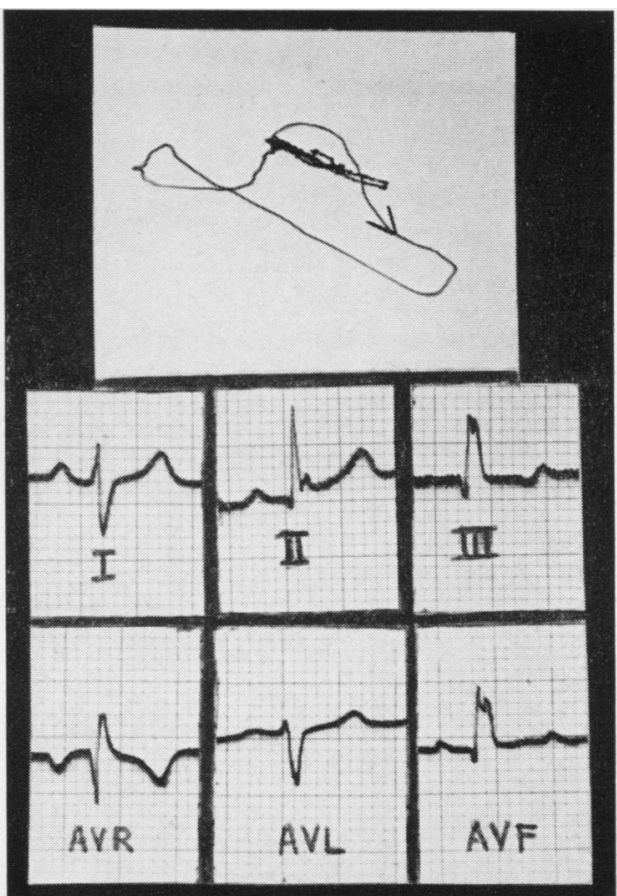

FIG. 3
FIGS. 1, 2, and 3. Examples of the classic type of vector cardiogram in an A.S.D. of the dorsal type. 


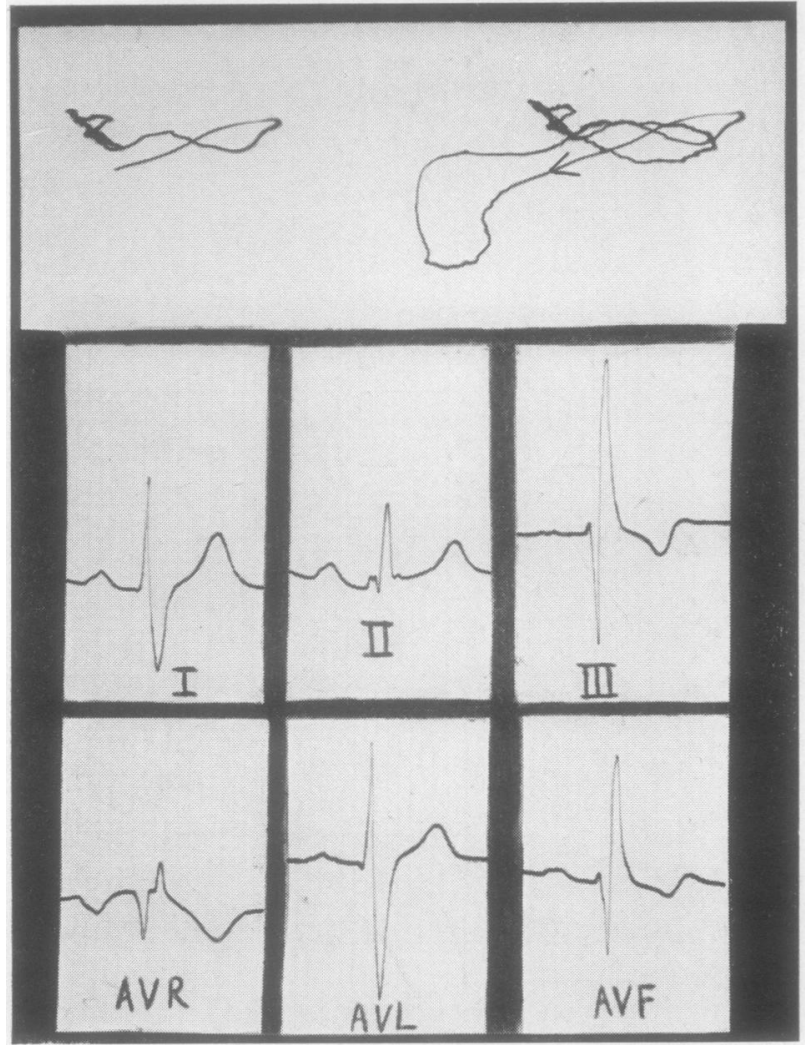

FIG. 4

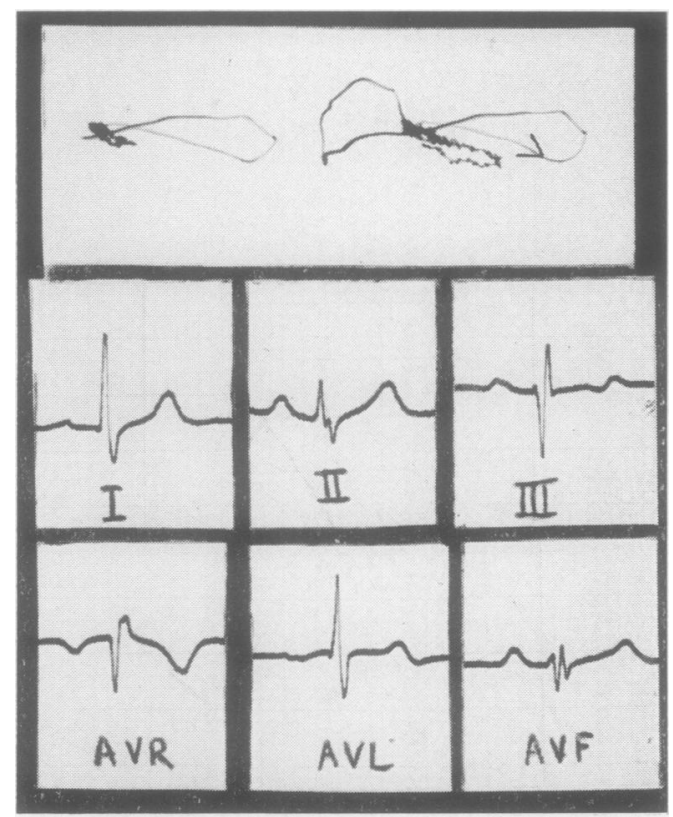

PIG. 6

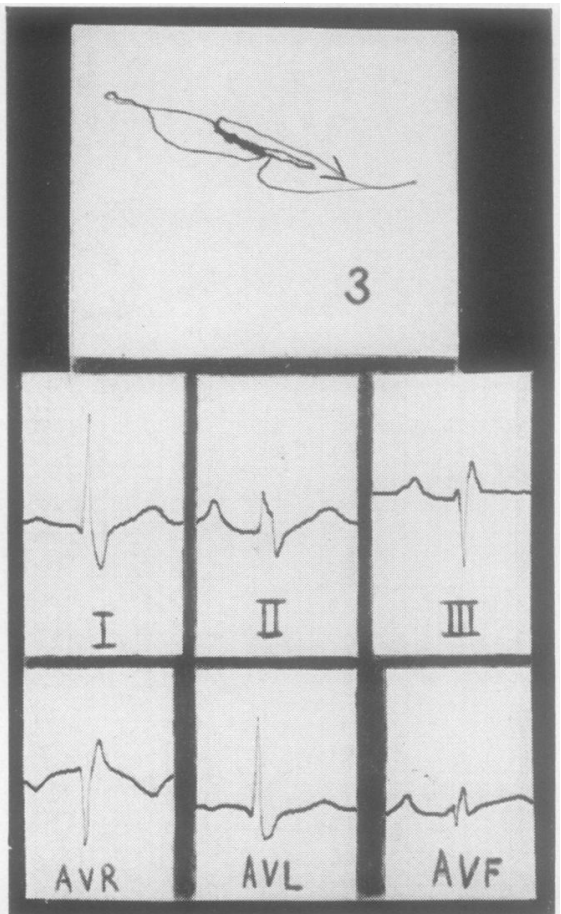

FIG. 5

FIGS. 4 and 5. Examples of the non-classic type of vector cardiogram in a dorsal A.S.D.

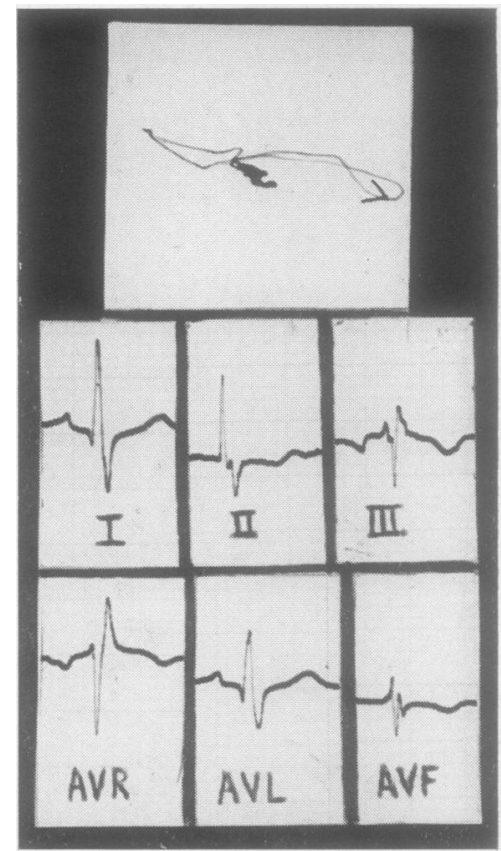

FIG. 7

FIGS. 6 and 7. Examples of a figure-of-eight vector loop in the frontal plane in a dorsal A.S.D. 


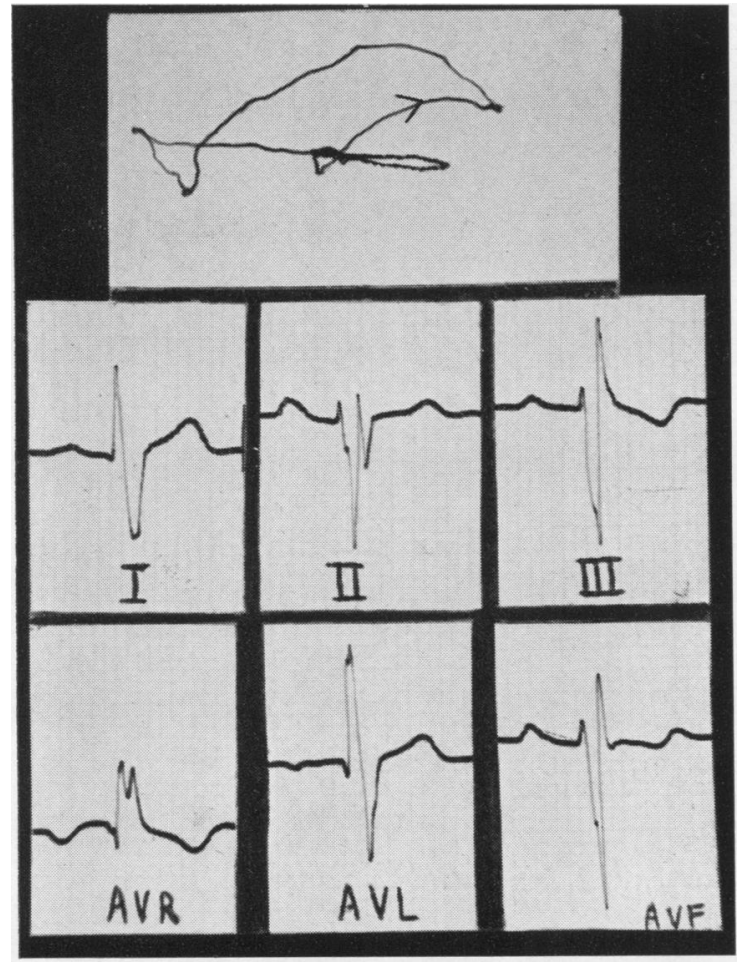

FIG. 8. Example of a vector loop compatible with an A.S.D. of the ventral type.
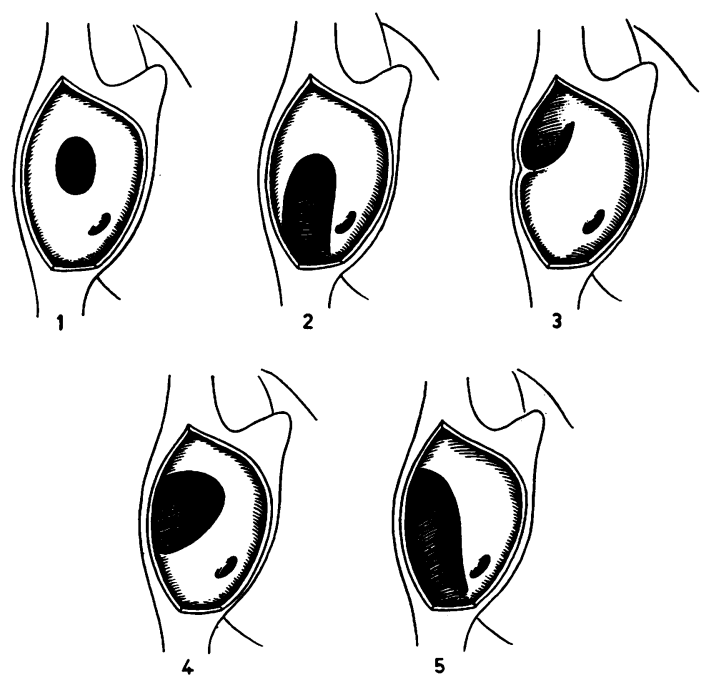

FIG. 9. Dorsal ('secundum') types of atrial septal defect. For explanation see text.
VENTRAL ('PRIMUM') DEFECT Unlike the dorsal type, this defect has no edge on the side of the atrioventricular valves. Its localization is ventral to the coronary sinus (Fig. 10).

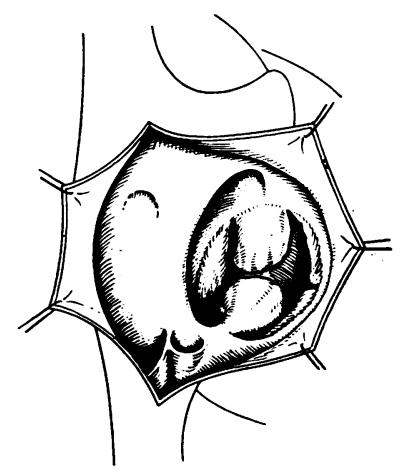

FIG. 10. Ventral ('primum') type of atrial septal defect.

\section{RESULTS}

Table I shows clearly how well the vector cardiographic findings and anatomical types of defect found at operation correlate.

\section{TABLE I}

CORRELATION BETWEEN ANATOMY AND VECTOR CARDIOGRAM IN VENTRAL AND DORSAL ATRIAL SEPTAL DEFECTS

\begin{tabular}{lcc} 
Vector Cardiogram & \multicolumn{2}{l}{ Anatomy } \\
\cline { 2 - 3 } & Ventral Defect & Dorsal Defect \\
\hline Dorsal type & 1 & 152 \\
Ventral type & 28 & 2
\end{tabular}

The following is a more detailed consideration of the classification. In a group of 152 patients with a vector cardiogram of the dorsal type and a dorsal atrial septal defect an attempt was made to establish a correlation between the type of vector cardiogram and the anatomical findings at operation. As pointed out, the vector cardiograms of the dorsal

T ABLE II

CORRELATION BETWEEN ANATOMY AND VECTOR CARDIOGRAM IN DORSAL TYPES OF A.S.D.

\begin{tabular}{lrrrrrr}
$\begin{array}{l}\text { Vector Cardio- } \\
\text { graphic Type } \\
\text { of Dorsal A.S.D. }\end{array}$ & \multicolumn{6}{c}{ Anatomical Type of Dorsal Defect } \\
\cline { 2 - 7 } & 1 & 2 & 3 & 4 & 5 & Total \\
\hline 1 & 77 & 10 & 13 & 2 & 2 & 104 \\
2 & 17 & 6 & 5 & 1 & 4 & 33 \\
3 & 5 & 4 & 2 & 1 & 3 & 15 \\
Total & 99 & 20 & 20 & 4 & 9 & 152
\end{tabular}




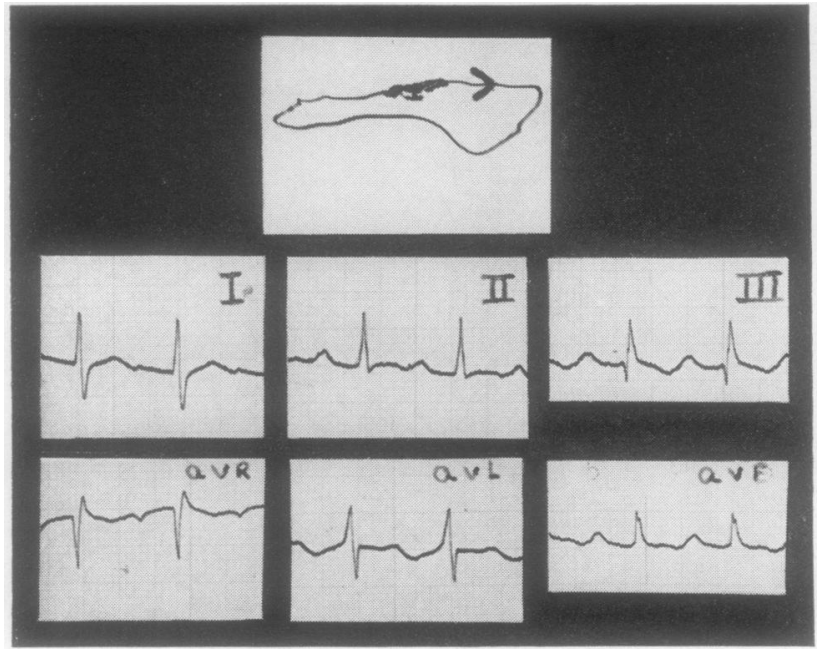

FIG. 11. In the frontal plane the loop shows a clockwise downward course. In its frontal projection this vector loop meets the criteria of a classic vector cardiogram in a dorsal type of A.S.D. At operation, however, a typical ventral A.S.D. was found.

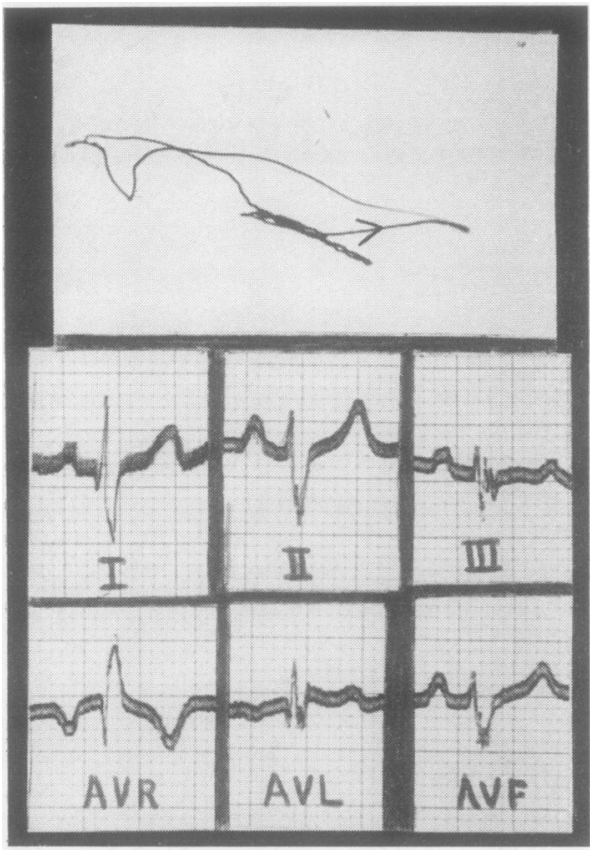

FIG. 12

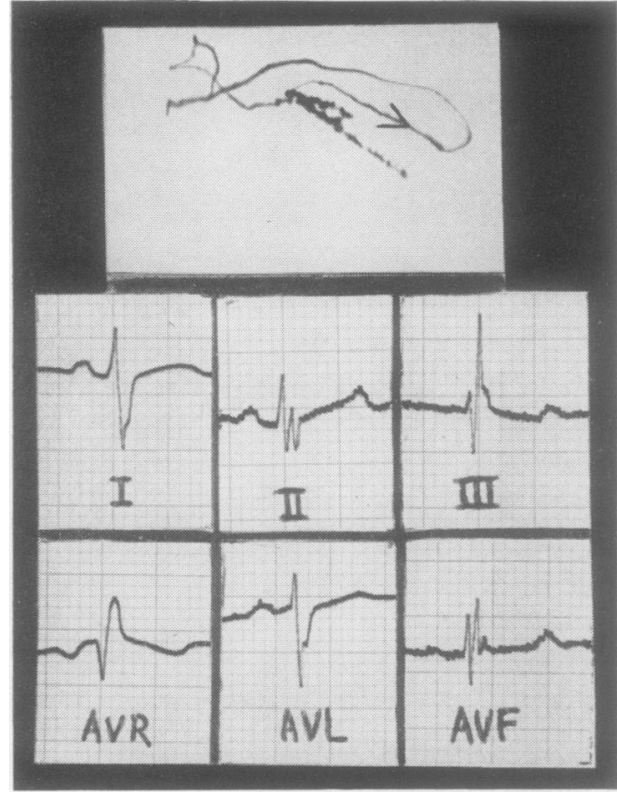

FIG. 13

FIGS. 12 and 13. Both vector cardiograms show a frontal projection of the QRS loop which has an upward counter-clockwise course. 
type were divided into groups 1,2 , and 3 , and five anatomical groups were distinguished (Table II). The figures in the various columns were too small to permit further elaboration. The anatomical groups were therefore exclusively divided into (1) a central defect, and (2) other types of defect (groups 2, 3, 4, and 5 together). This gives the classification shown in Tables III and IV. This

\section{TABLE III}

SIMPLIFIED CLASSIFICATION OF CORRELATION BETWEEN ANATOMY AND VECTOR CARDIOGRAM IN DORSAL TYPES OF A.S.D.

\begin{tabular}{|c|c|c|c|}
\hline \multirow{2}{*}{$\begin{array}{l}\text { Vector Cardio- } \\
\text { graphic Type } \\
\text { of Dorsal } \\
\text { A.S.D. }\end{array}$} & \multicolumn{3}{|c|}{ Anatomical Type of Dorsal Defect } \\
\hline & $\begin{array}{l}\text { Central } \\
\text { Defect }\end{array}$ & Other & Total \\
\hline $\begin{array}{l}1 \\
2 \\
3\end{array}$ & $\begin{array}{r}77 \\
17 \\
5\end{array}$ & $\begin{array}{l}27 \\
16 \\
10\end{array}$ & $\begin{array}{r}104 \\
33 \\
15\end{array}$ \\
\hline Total & 99 & 53 & 152 \\
\hline
\end{tabular}

TABLE IV

PERCENTAGE DISTRIBUTION OF VECTOR-CARDIOGRAPHIC AND ANATOMICAL TYPES OF DORSAL A.S.D. IN 152 PATIENTS

\begin{tabular}{|c|c|c|c|}
\hline \multirow{2}{*}{$\begin{array}{l}\text { Vector Cardio- } \\
\text { graphic Type } \\
\text { of Dorsal } \\
\text { A.S.D. }\end{array}$} & \multicolumn{3}{|c|}{ Anatomical Type of Dorsal Defect } \\
\hline & $\begin{array}{l}\text { Central } \\
\text { Defect }\end{array}$ & Other & Total \\
\hline $\begin{array}{l}1 \\
2 \\
3\end{array}$ & $\begin{array}{l}74 \cdot 0 \\
51 \cdot 5 \\
33 \cdot 3\end{array}$ & $\begin{array}{l}26 \cdot 0 \\
48 \cdot 5 \\
66 \cdot 7\end{array}$ & $\begin{array}{l}100 \\
100 \\
100\end{array}$ \\
\hline Total & $65 \cdot 1$ & 34.9 & 100 \\
\hline
\end{tabular}

means that a central atrial septal defect was present in three out of four patients showing a type 1 vector cardiogram. With a type 2 vector cardiogram there are equal chances of a central defect or some other type of dorsal A.S.D. In a type 3 vector cardiogram twice as many other types as central defects were found. The likelihood that the relations found in Table IV are based on coincidence is smaller than $0.01\left(\chi_{(2)}^{2}=13 \cdot 14\right)$.
Twenty-eight patients had a type 4 vector cardiogram (ventral type) conforming with the description given in Fig. 8. At operation a typical ventral A.S.D. was found (Fig. 10).

One patient with the anatomy of a ventral defect had a vector cardiogram indicating a dorsal defect (Fig. 11).

Two patients with the anatomy of a dorsal defect had a vector cardiogram indicating a ventral defect (Figs. 12 and 13). They meet the requirements of a vector loop in a ventral A.S.D. In patient A (Fig. 12) a dorsal A.S.D. of the central type was found at operation. In patient B (Fig. 13) a dorsal A.S.D. without a caudal edge was found at operation.

\section{SUMMARY}

A study of 183 patients confirmed the experience of others that the vector cardiogram is a valuable aid in the differentiation between ventral ('primum') and dorsal ('secundum') atrial septal defects.

A description is given of a few patients in whom the vector cardiogram led to an incorrect prediction.

In patients with a dorsal A.S.D. there is a relation between the vector cardiogram and the anatomical type of defect.

We are indebted to Mr. P. van Leeuwen, of the Department of Statistics of the Netherlands Institute of Preventive Medicine, for his valuable help.

\section{REFERENCES}

Burger, H. C., van Milaan, J. B., and Den Boer, W. (1952). Brit. Heart J., 14, 401

Hamer, N. A. J. (1958). Ibid., 20, 215.

Liebman, J., and Nadas, A. S. (1960). Circulation, 22, 956.

Los, I. A. (1963). In the press.

Pileggi, F., Boccalandro, I., Ebaid, M., Malleta, C. A., Tranchesi, J., Macruz, R., and Décourt, L. V. (1961). Amer. Heart J., 62, 447. Silverblatt, M. L., Rosenfeld, I., Grishman, A., and Donoso, E. (1957). Ibid., 533, 380.

Toscano-Barbosa, E., Brandenburg, R. O., and Burchell, H. B. (1956). Proc. Mayo Clin., 31. 513. 